\title{
Monoclonal antibody that detects human type I muscle fibres in routinely fixed wax embedded sections
}

\author{
A DODSON, ${ }^{*}$ J GARSON $\ddagger$ M BURKE, ${ }^{*}$ B H ANDERTON $\dagger$
}

From the Departments of *Histopathology and †Immunology, St George's Hospital Medical School, London, and the ‡Oncology Laboratory, Imperial Cancer Research Fund Laboratories, Institute of Child Health, London

SUMMARY A murine monoclonal antibody, F7, which selectively shows type I fibres in human skeletal muscle is reported. The antibody reacts with frozen sections and with formalin fixed wax embedded material. It should prove useful in the retrospective and prospective study of muscle pathology.

Fibre type analysis is an important procedure in the study of normal and diseased skeletal muscle. The discrimination of fibre types is routinely achieved by the use of enzyme histochemical techniques, and in particular that for adenosine triphosphatase (ATPase) after preincubation at various $\mathrm{pH}$ values. ${ }^{1}$ Fibre type differentiation has also been shown immunocytochemically by the use of a monoclonal antibody that recognises type II muscle fibre ${ }^{2}$ and by the use of polyclonal antisera raised against various muscle proteins. ${ }^{3-5}$

We report here a monoclonal antibody, F7, that reacts selectively with human type I skeletal muscle fibres. This antibody may be used on frozen sections and on formalin fixed wax embedded sections.

\section{Material and methods}

\section{MONOCLONAL ANTIBODIES}

Monoclonal antibodies were produced, as previously described. ${ }^{6}$ Monoclonal antibody, F7, was produced from a fusion using the cells from the spleen of a BALB/c mouse that had been immunised with a Triton-X-100 insoluble fraction from human brain stem; these were fused with the cells of the murine myeloma cell line P3 X63.Ag.8.653 (Flow Laboratories). Hybridoma cells were cloned by limiting dilution. The observation by one of us (JG) that the clone designated F7 produces antibody, which reacts selectively with type I muscle fibres, was an incidental finding. F7 is of immunoglobulin class IgG2b.

The monoclonal antibody BE4 is an antinuclear histone protein antibody. ${ }^{7}$ It was used here as a control to test for non-specific antibody binding.

Accepted for publication 24 July 1986
TISSUE

Normal human skeletal muscle tissue was obtained by surgical procedure. The tissue was rapidly frozen in isopentane cooled by liquid nitrogen. Cryostat sections transverse to the orientation of muscle fibres were prepared at $6 \mu \mathrm{m}$, and these were used for enzyme histochemistry and immunocytochemistry The tissue was then fixed overnight at room tem perature in phosphate buffered $10 \%$ formalin and processed using routine reagents and procedures to paraffin wax. Sections were cut from the same face of the tissue and in the same orientation as the cryostat sections. These sections were used for immunocytochemical staining.

\section{ENZYME HISTOCHEMISTRY}

Cryostat sections were used to show ATPase activity at $\mathrm{pH} 9 \cdot 4 .^{1}$

\section{IMMUNOCY TOCHEMISTR Y}

Cryostat sections were stained using the indirect immunoperoxidase technique. The primary antibodies F7 and BE4 were applied as tissue culture supernatants to unfixed sections that had been previously rinsed in Tris buffered saline (TBS) at $\mathrm{pH} 7 \cdot 4$. Tissue culture supernatant that had been conditioned by the growth of P3 X.63.Ag.8.653 cells was similarly used and served as a negative control. Incubation was at room temperature for 60 minutes. After thorough washing in TBS sections were incubated with peroxidase conjugated rabbit antimouse Ig antibody diluted $1 / 25$ in TBS (Dakopatts) for 60 minutes at room temperature. After washing in TBS peroxidase activity was shown using hydrogen peroxide and diaminobenzidine (Sigma). Sections were dehydrated, cleared, and mounted in DPX (RA Lamb). Paraffin sections were also stained using the indirect immuno- 


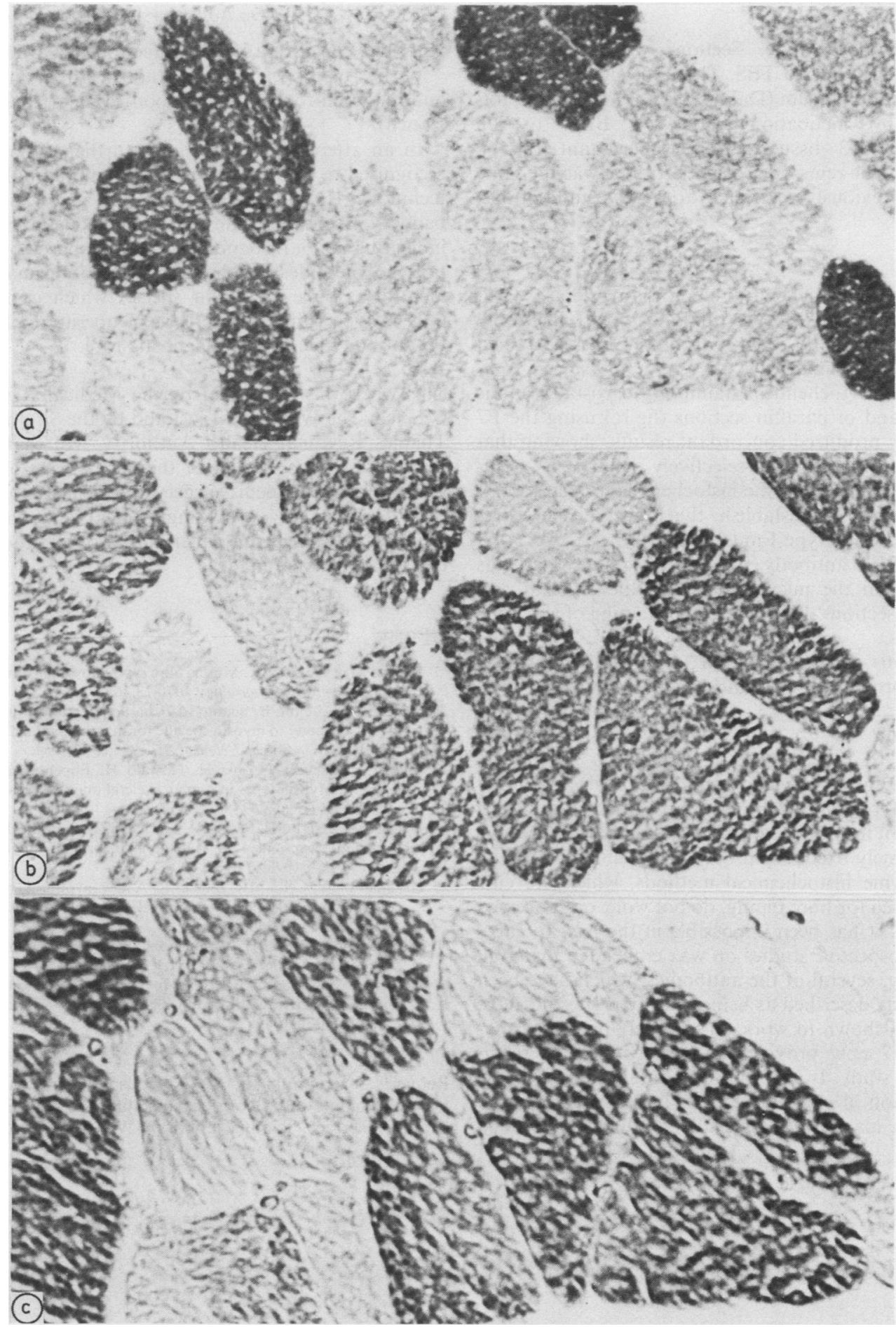

Figure (a) Cryostat section of human skeletal muscle stained by enzyme histochemical method for ATPase ( $\mathrm{pH}$ 9.4); (b) cryostat section showing similar field to that in (a), stained by indirect immunoperoxidase technique using antibody $F 7 ;(c)$ paraffin section stained by antibody $F 7$, similar field to that shown in $(a)$ and $(b)$. 
peroxidase technique. Sections were dewaxed in xylene and taken to TBS. They were incubated with normal rabbit serum (Dakopatts) for $\mathbf{3 0}$ minutes, followed by incubation with F7, BE4, or P3 X.63.Ag.8.653 tissue culture supernatant for 60 minutes. The remainder of the protocol was the same as that previously described for the cryostat sections.

\section{Results}

The enzyme histochemical method for ATPase at $\mathrm{pH}$ 9.4 differentiated the type I muscle fibres, which were negative to lightly stained from the darkly stained type II fibres (fig la).

Immunocytochemical staining of cryostat sections (fig lb) and of paraffin sections (fig lc) using the F7 antibody produced concordant results, showing that a subset of fibres was selectively stained. By comparison with the enzyme histochemical preparation it was possible to establish that this subset corresponded to the type I muscle fibres.

The BE4 antibody produced staining that was confined to the nuclei present in the cryostat and paraffin sections. BE4 showed no staining of any muscle fibres.

Sections incubated with P3 X63.Ag.8.653 supernatant produced no staining.

\section{Discussion}

We have shown that the antibody F7 selectively recognises type I muscle fibres in human skeletal muscle and that it may be used to carry out fibre type analysis on routinely fixed and processed specimens. Because the enzyme histochemical methods, which are currently used for fibre typing, do not work on processed material, it has been impossible in the past to carry out retrospective studies on wax embedded material. Similarly, several of the antibodies, which have been previously described as being fibre type specific, have not been shown to work on routinely processed material. F7 now provides an opportunity for retrospective study. It also provides an alternative to the production of cryostat sections in prospective work, and this may prove especially useful when dealing with material with a known infectious hazard.

F7 has also been used to stain necropsy material and has been found to give good results (results not shown).

In an attempt to characterise further the antigen recognised by $\mathrm{F} 7$ it has been used in immunoblotting techniques (results not shown). It gives multiple bands with homogenates of whole skeletal muscle, indicating that it recognises an epitope shared by multiple polypeptides. We have thus far been unable to identify a single molecular species which is present only in type I fibres; nevertheless, operationally, the F7 antibody is a useful diagnostic tool.

This work was supported by the Medical Research Council, The Wellcome Trust and by the South West Thames Regional Health Authority. We thank Dr Betty Brownell and staff of the department of neuropathology and neurosurgery, Frenchay Hospital, Bristol, for kindly providing clinical material and technical support from which initial observations of this antibody were made.

\section{References}

1 Brooke MH, Kaiser KK. Muscle fibre types: how many and what kind? Archives of Neurology 1970;23:369-79.

2 Sawchak JA, Leung B, Shafig SA. Characterization of a monoclonal antibody to myosin specific for mammalian and human type II muscle fibres. J Neurol Sci 1985;69:247-54.

3 Billeter R, Weber H, Lutz H, Howald H, Eppenberger HM Jenny E. Myosin types in human skeletal muscle fibres. Histochemistry 1975;65:249-59.

4 Dhoot GK, Gell PGH, Perry SV. The localization of the different forms of Troponin I in skeletal and cardiac muscle cells. Exp Cell Res 1978;117:357-70.

5 Heizmann CW, Celio MR, Billeter R. A new myofibrillar protein characteristic of type I human skeletal muscle fibres. Eur $J$ Biochem 1983;132:657-62.

6 Wood JN, Anderton BH. Monoclonal antibodies to mammalian neurofilaments. Biosci Rep 1981;1:263-8.

7 Downes MJ, Anderton BH, Garson J, Allen J. A monoclonal antibody reactive with the tail regions of core histones. Biol Cell 1982;45:121-4.

Requests for reprints to: Mr A Dodson, Department of Histopathology, St George's Hospital Medical School, Cranmer Terrace, Tooting, London SW17 0RE, England. 